\title{
EVALUATION OF A SINGLE PUNCTURE VERSUS A DOUBLE PUNCTURE ARTHROCENTSESIS TECHNIQUE IN THE TREATMENT OF ANTERIOR DISC DISPLACEMENT WITHOUT REDUCTION: A PROSPECTIVE RANDOMIZED STUDY
}

\author{
Mostafa Talaat El Gengehy*, Ayman Gouda** and Usama M Taema***
}

\begin{abstract}
AIM: the aim of this study was to compare patient satisfaction and the clinical outcome of single needle approach versus double needle technique in treating patients with anterior disc displacement without reduction.
\end{abstract}

Patients and Methods: This was a randomized controlled trial conducted on 14 adult (13 females and 1 male) patients with anterior disc displacement without reduction with limiting opening. In control group, double needle TMJ arthrocentsesis was performed with $100 \mathrm{ml}$ ringer's lactate solution. While in the test group, single needle TMJ arthrocentsesis was performed with 21 $\mathrm{ml}$ ringer's lactate solution. All patients were followed up for 3 months. Pain level and maximum mouth opening were evaluated in both groups.

Results: Both groups showed a significant improvement throughout the study intervals.

Conclusions: Single needle arthrocentsesis represents a reliable treatment modality for the management of patients suffering from closed lock. However the exact amount of irrigation solution needed to achieve the maximum therapeutic benefits from this technique is a point that needs further investigations.

KEYWORDS: Temporomandibular joint, Closed lock, Arthrocentsesis, Single needle, Double needle.

\section{INTRODUCTION}

Internal derangement of TMJ is a general term used to describe a wide variety of clinical sign and symptoms that results from a disruption in the relationship between the articular disc with the condylar head and articular surface of temporal bone. Thus, the term has been used tandem with disc displacement. ${ }^{1}$

Since its introduction in 1991 by Nitzan et al ${ }^{2}$, arthrocentsesis is considered by TMJ specialists all

\footnotetext{
* Lecturer, Oral and Maxillofacial Surgery Department, Faculty of Dentistry, Cairo University, Cairo, Egypt.
} 
over the world to be the last hope for those patients who failed to respond to non-surgical treatment modalities before heading forward toward more radical irreversible surgical treatments. ${ }^{3}$

However, in spite of the proven success of the standard double needle technique in treating different forms of internal derangement ${ }^{4}$, yet the (blind)insertion of the second needle is considered to be quite challenging especially in the presence of intra-articular adhesions which may increase the post-operative morbidity and patient discomfort. ${ }^{5}$

In 2008, Nardini et al ${ }^{6}$ Suggested a new technique based on the abandonment of the second needle for the favor of using only single needle for both fluid injection and aspiration. Unlike the double needle technique, the proposed technique expands -rather than flushing - the upper joint space by injecting the irrigation fluid under high pressure by eliminating the second (outlet) needle. However, although Nardini et $\mathrm{al}^{6}$ suggesting using $4 \mathrm{ml}$ (repeated 10 times ) to distend the joint, yet, how much of irrigation fluid can be used safely to distant the joint while providing minimal discomfort to the patient is a question that was not yet addressed by researchers.

This study is designed to compare patient satisfaction and the clinical outcome of single needle approach versus double needle technique in treating patients with anterior disc displacement without reduction.

\section{PATIENTS AND METHODS}

\section{A) Study setting}

This study included fourteen TMJ single and double needle arthrocentsesis conducted on fourteen patients (13 females and 1 male aged between 28 to 49 years with a mean of age of 37 years, $S D \pm 5.4$ ). The patients were selected from the outpatient clinic of the Oral and Maxillofacial Surgery Department Cairo University. The Patients were divided into two equal groups, seven patients each (test and control
groups).The test group underwent TMJ single needle arthrocentsesis using $21 \mathrm{ml}$ ringer lactate. The injection-ejection process was performed for up to 7 repetitions $(3 \mathrm{ml} \times 7)$.

On the other hand, the control group received a standard double needle TMJ arthrocentsesis using $200 \mathrm{ml}$ ringer lactate.

The study was a double blinded one (participants and outcome assessors were blinded throughout the study).

\section{B) Patient selection}

The selected patients were selected after a throughout clinical examination based the $\mathrm{CD} /$ TMD Axis I diagnostic algorithm ${ }^{7}$ and only patients suffering from anterior disc displacement without reduction with limited mouth opening were included in the study. Diagnostic MRI was not used in this study since the DC/TMD diagnostic criteria for closed lock have sensitivity of 0.80 and specificity $0.97 .^{7}$

\section{I- Inclusion criteria}

Patients fulfill CD/TMD diagnostic criteria to be diagnosed as disc displacement without reduction with limited mouth opening (closed lock) which include the following

1. Locked jaw that does not open all the way and interferes with the ability to eat.

2. Maximum assisted moth opening is less than 40 $\mathrm{mm}$.

\section{II- Exclusion criteria}

1. Presence of systemic conditions that may affect treatment outcome (e.g. rheumatoid arthritis).

2. Patient suffering from limited jaw opening related to muscular disorders ( e.g. myofacial pain)

3. History of previous TMJ surgery and/or mandibular trauma 
4. History of psychological disorder that may affect pain perception.

\section{C) Intervention}

\section{I-Pre-operative preparation}

For both groups the preoperative pain level was determined using the Visual Analogue Scale (VAS) that ranges from 0-10 with zero indicating no pain while 10 indicating the worst pain. In addition to the preoperative pain level, the preoperative maximum assisted mouth opening was also evaluated.

\section{II-Intra-operative procedures (for test group)}

Following the administration of auriculo temporal nerve block, the single needle was introduced into the upper joint space through the entry point described by Nitzan et al ${ }^{2}$ located $10 \mathrm{~mm}$ anterior to the tragus and $2 \mathrm{~mm}$ below imaginary canthal-tragus line (Holmlund-Hellsing line). A 21gauge needle was inserted into the upper joint space followed by the injection of $3 \mathrm{ml}$ Ringer solution at the opening position to distend the joint space under pressure. Then the syringe was removed to allow ejection out of the injected fluid while the patient is force fully closing his mouth. The injection-ejection cycles were continued for a total of $21 \mathrm{ml}$ of lactated Ringer's solution. (Figure1-a)

\section{III- Intra-operative procedures (for control group)}

Following the administration of auriculotemporal nerve block, the standard double needle technique described by Nitzan et al ${ }^{2}$ was applied where the first needle was introduced into the upper joint space located $10 \mathrm{~mm}$ anterior to the tragus and $2 \mathrm{~mm}$ below imaginary canthal-tragal line, followed by injecting $3 \mathrm{ml}$ ringer lactate to induce joint distension and to confirm intra-articular needle positioning. The second needle was then introduced $20 \mathrm{~mm}$ anterior to the tragus and $10 \mathrm{~mm}$ below the imaginary canthaltragus line. Lavage process was then completed using $100 \mathrm{ml}$ ringer's lactate. (Figure1-b)

For both groups the following intra-operative parameters were recorded and evaluated

1. Degree of patient discomfort (i.e. procedure tolerability) via VAS.

2. Time of procedure execution (excluding the time needed to administrate the auriculotemporal nerve block).

\section{D- Post-operative evaluation.}

Pain level and the maximum mouth opening were evaluated both at 1 month and 3 months postoperatively.

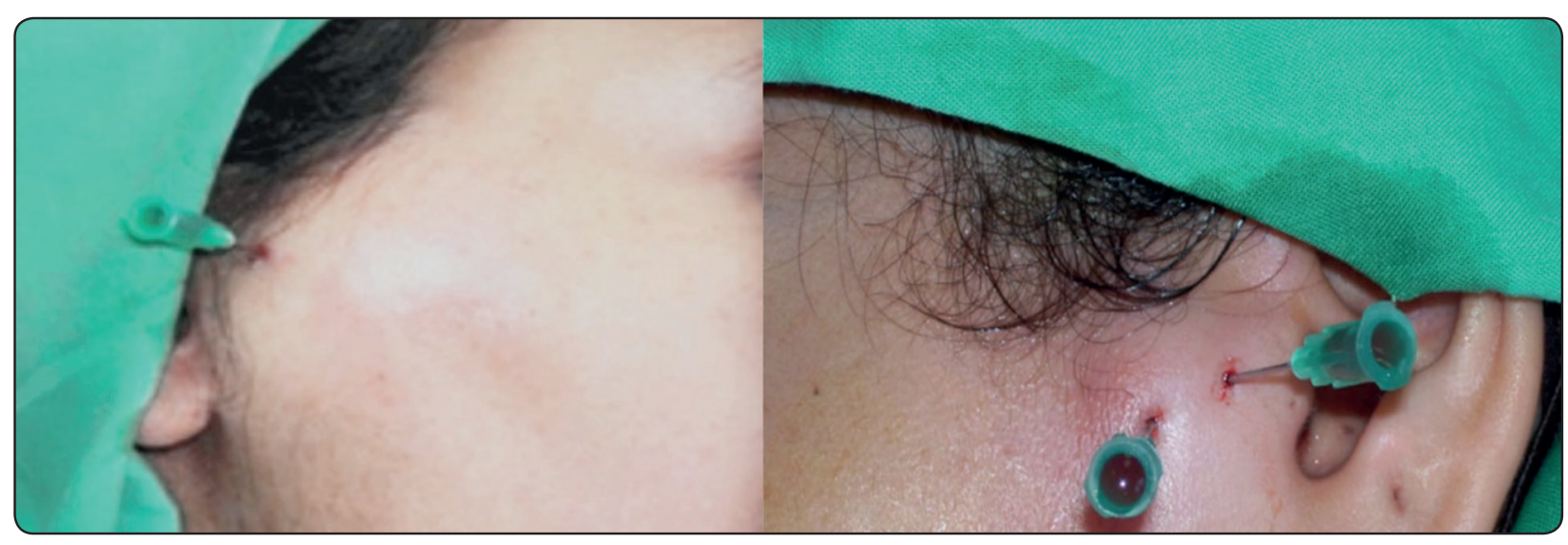

Figure $1 \mathrm{a}$ and $1 \mathrm{~b}$ showing single needle technique and double needle technique respectively 


\section{RESULTS}

In this study 14 patients were included (13 females and 1 male), with their mean age $37 \pm 5.4$ years (range from 28-49 years). All patientshad disc displacement without reduction with limiting opening. All patients were followed- up for 3 months. Pre-treatment and the follow up data were collected at one month and three months)

The assessment between different follow up was done by paired ' $\mathrm{t}$ ' test and Mcnemar chi square test. The result was considered significant if $\mathrm{p}$ value was $<0.05$.

\section{Degree of patient discomfort (i.e. procedure tolerability)}

A statistically significant difference ( $\mathrm{p}$ value 0.03 ) was shown between the two groups regarding procedure tolerability as the VAS score for the test group was $3.57 \pm 1$ while on the other hand the test group recorded a higher score of $4.7 \pm 0.75$. (Figure 2)

\section{Time of procedure execution}

A statistically significant difference was shown between the two groups regarding timing of procedure. In the test group time elicited to complete the procedure was $14.8 \pm 1.34$ minutes while for control group time taken was $23.42 \pm 3.25$ ( $\mathrm{p}$ value 0.00003). (Figure 3)

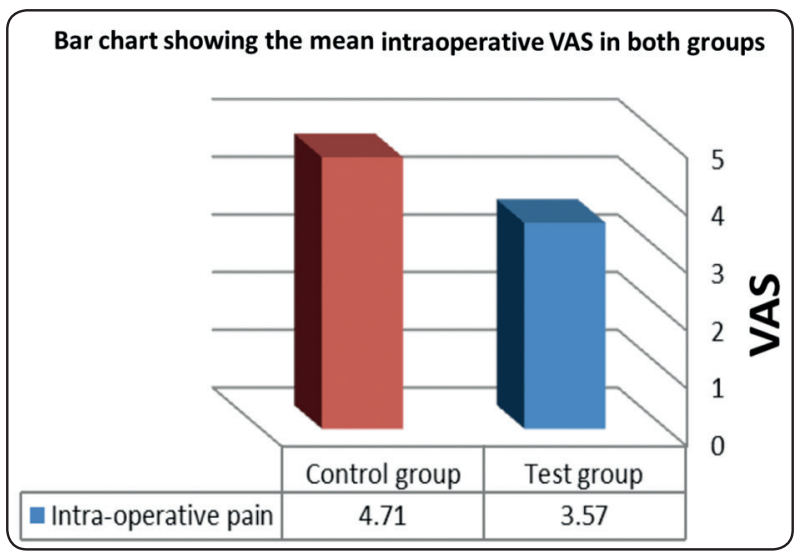

Fig. (2) Bar chart showing the mean intra-operative VAS for both groups

\section{Pain score}

The subjective data elicited from VAS scores showed significant reduction in pain in test group from mean $6.57 \pm 0.97$ to $3.42 \pm 1.27$ and $2.85 \pm 0.69$ at 1 month and 3 months follow up periods respectively and for control group from mean $6.28 \pm 1.49$ to $3.14 \pm 1.06$ and $2.57 \pm 0.53$ at 1 month and 3 months follow up periods respectively. (Figure 4). The statistical analysis showed that both groups revealed a statistically significant decrease in pain level throughout the entire study intervals. Comparing the results of the two groups failed to show a statistically significant difference between them in the 1 month and 3 months follow-up period as the $\mathrm{p}$ value was 0.65 and 0.4 respectively.

\section{Maximum mouth opening (MMO)}

MMO has significantly increased $(\mathrm{p}<0.05)$ for the test group from $17.57 \pm 1.98 \mathrm{mms}$ to $30.57 \pm 1.81 \mathrm{~mm}$ and $30.71 \pm 1.79 \mathrm{~mm}$ at one month and three months postoperatively while for control group $\mathrm{MMO}$ has increased from $16.85 \pm 1.67 \mathrm{mms}$ to $33.14 \pm 1.67 \mathrm{~mm}$ and $33.42 \pm 1.71 \mathrm{~mm} \mathrm{mms}$ at one month and three months respectively. (Figure 5)

On comparing the improvement of the $\mathrm{MMO}$ in both groups, the control group showed a statistically significant improvement compared to the test group with $P$ valve 0.017 and 0.013 at 1 and 3 months follow up

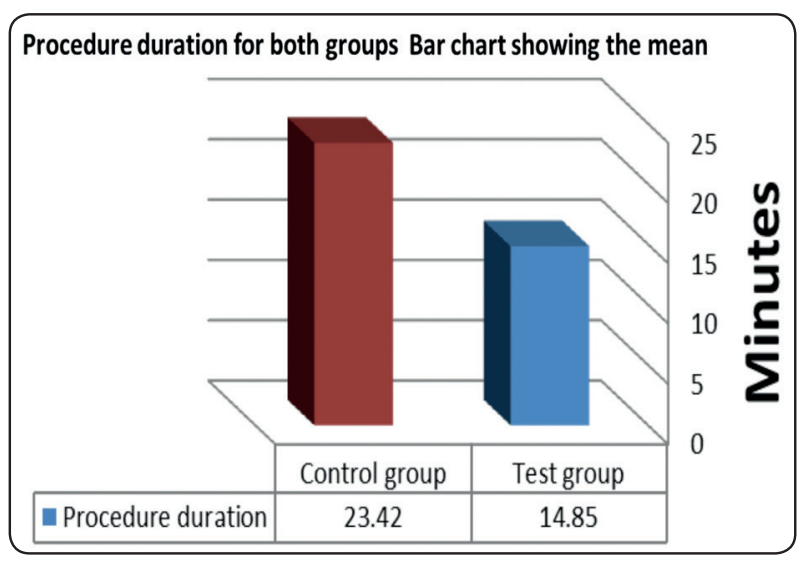

Fig. (3) Bar chart showing the mean procedure duration for both groups 


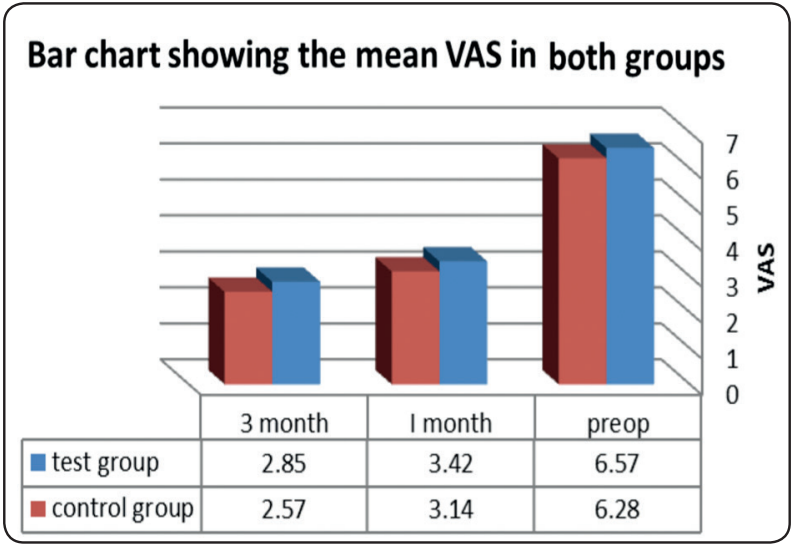

Fig. (4) Bar chart showing the mean VAS for both groups during different time intervals

\section{DISCUSSION}

After its recognized and proven success in treating large joints, ${ }^{8-11}$ Nitzan $^{2}$ adopted the concept of joint lavage in treating patients suffering from TMJ disorders mainly closed lock and disc adhesions

In spite of the fact that the standard double needle technique is a simple and minimally invasive procedure, yet still its use is associated with intra and post-operative complications. Most of these complications are attributed to the blind insertion of the second - out flow needle or its frequent dislodgment during the procedure, which in turn increase the intra-operative time $\&$ patient discomfort. ${ }^{12.13}$

In an attempt to overcome this drawback, a modifications for the placement of the second needle were suggested either by putting it 2-3 $\mathrm{mm}$ in front of the entry point ${ }^{14}$ or 2-3 mm behind $i^{15}$. This was supposed to allow an easy and reproducible needle insertion into the wider area of the upper joint space.

Although TMJ arthrocentsesis can be performed using normal saline, yet in this study ringer's lactate was preferred over saline since its considered to be better tolerated by the cellular components of the TMJ disc. ${ }^{16}$ The amount of irrigation using in the double needle group was selected based on previous

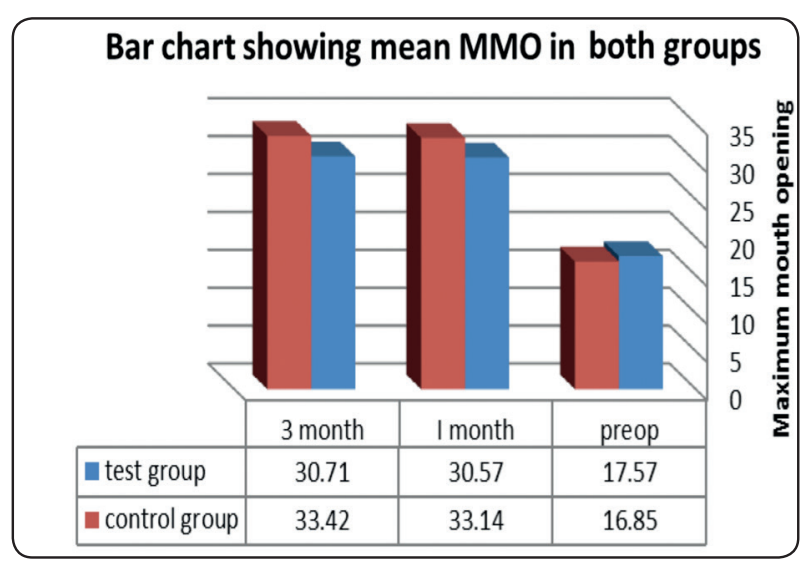

Fig. (5) Bar chart showing the mean MMO for both groups during different time intervals

studies that showed that $100 \mathrm{ml}$ of irrigation solution is the minimal amount needed to clear the upper joint space from denatured hemoglobin and various proteinases..$^{17-18}$

Introduced by Nardini et $\mathrm{al}^{6}$, the single needle technique aimed to improve the tolerability and reduce the complications of the double needle technique by using only one needle for both injection and ejection of the irrigation solution and completely avoiding the second needle.

The results of this study show that the test group showed less operative time and pain $14.8 \pm 1.34$ and $3.57 \pm 1$ respectively compared to the control group $23.42 \pm 3.25$ and $4.7 \pm 0.75$. The difference was statistically significant. These results can be explained by the relatively atraumatic nature of the single needle technique and the minimal amount of irrigation used compared to the standard double needle technique.

The subjective data elicited from the VAS showed a significant reduction in pain in both groups from $6.57 \pm 0.97$ to $2.85 \pm 0.69$ for the study group and from $6.28 \pm 1.49$ to $2.57 \pm 0.53$ for the control group. The difference between both groups was statistically insignificant. These results are consistent with previous studies ${ }^{19-20}$ that compared 
the efficiency of both techniques in reducing joint paint.

On the other hand, although the maximum mouth opening was significantly improved in the test group from $17.57 \pm 1.98$ to $30.71 \pm 1.79$.yet this improvement with less than that encountered with the control group that increased from $16.85 \pm 1.67$ to $33.42 \pm 1.71$, the difference between both groups was statistically significant for the favor of the control group.

These results can be explained due to the use of only $21 \mathrm{ml}$ ringer lactate to perform the single needle technique. The selection of such little amount of irrigation solution was selected based on the study performed by Sindelet $\mathrm{al}^{21}$ that proved that $20 \mathrm{ml}$ was enough to eliminate methylene blue solution injected into the TMJ of fresh cadavers and similarly he speculated that only $20 \mathrm{ml}$ will be enough to clear the inflammatory mediators from the joint. However, although this was true regarding decreasing the level of pain, yet apparently $21 \mathrm{ml}$ was not sufficient to efficiently break the intraarticular adhesions.

It worth mentioning that the improvement in the maximum mouth opening was greater than that recorded in the previous study performed by Gouda et $\mathrm{al}^{22}$ which reflects the fact that the amount used in the expanding the joint in each time $(3 \mathrm{ml}$ in this study versus $2 \mathrm{ml}$ in the previous study) play a more important role than the total amount of the solution used ( $21 \mathrm{ml}$ versus 40 in the previous study).

\section{CONCLUSIONS}

Single needle arthrocentsesis represents a reliable treatment modality for the management of patients suffering from closed lock. However the exact amount of irrigation solution needed to achieve the maximum therapeutic benefits from this technique is a point that needs further investigations.

\section{REFERENCES}

1- Emshoff R and Rudish A. Tempromandibular Joint internal derangement and osteoarthrosis: Are effusion and bone marrow edema prognostic indicators for arthrocentesis and hydraulic distension. J Oral Maxillofac Surg; 65:73, 2007.

2- Nitzan DW, Franklin Dolwick M, Martinez GA. Temporomandibular joint arthrocentesis: a simplified treatment for severe, limited mouth opening. J Oral Maxillofac Surg; 49:1163-1167,1991.

3- Nagori SA, Roy Chowdhury SK, Thukral H, Jose A, Roychoudhury A. Single puncture versus standard double needle arthrocentesis for the management of temporomandibular joint disorders: A systematic review. J Oral Rehabil; 00:1-9, 2018.

4- Nitzan DW. Arthrocentesis-incentives for using this minimally invasive approach for temporomandibular disorders. Oral MaxillofacSurgClin North Am; 18:311$328,2006$.

5- Rahal A, Poirier J, Ahmarani C. Single-puncture arthrocentesis-introducing a new technique and a novel device. J Oral Maxillofac Surg; 67:1771-3.2009.

6- Guarda-Nardini L, Daniele MM and Giuseppe F. Arhtrocentesis of the tempromandibular joint: a proposal for a single needle technique. Oral Surg Oral Med Oral Pathol Oral Radiol Endod; 106:483-6, 2008.

7- Schiffman E et al. Diagnostic Criteria for Temporomandibular Disorders (DC/TMD) for Clinical and Research Applications: recommendations of the International RDC/TMD Consortium Network and Orofacial Pain Special Interest Group $\uparrow$. J Oral Facial Pain Headache; 28(1):6-27, 2014.

8- Siva C, Velazquez C, Mody A, Brasington R. Diagnosing acute monoarthritis in adults: a practical approach for the family physician. Am Fam Phys; 68:83-9, 2003.

9- Tallia AF, Cardone DA. Diagnostic and therapeutic injection of the ankle and foot. Am Fam Phys; 68:1356-62, 2003.

10- Cardone DA, Tallia AF. Diagnostic and therapeutic injection of the hip and knee. Am Fam Phys; 67:2147-5, 2003.

11- Tallia AF, Cardone DA. Diagnostic and therapeutic injection of the wrist and hand region. Am Fam Phys 2; 67:745-50, 2003. 
12- Tozoglu S, Al-Belasy FA, Dolwick MF. A review of techniques of lysis and lavage of the TMJ. Br J Oral Maxillofac Surg ; 49:302-9, 2011.

13- Şentürk MF, Tüzüner-Öncül AM, Cambazoğlu M. Prospective short term comparison of outcomes after single or double puncture arthrocentesis of the temporomandibular joint. Br J Oral Maxillofac Surg; 54:26-29, 2016.

14- Laskin DM, Greene CS, Hylander WL, Temporamandibular disorders: an evidence-based approach to diagnosis and treatment. Chicago Quintessence; 441-481, 2006.

15- Alkan A, Etöz OA. A new anatomical landmark to simplify temporomandibular joint arthrocentesis. Br J Oral Maxillofac Surg ;48(4):310-1,2010.

16- Shinjo H, Nakata K, Shino K, et al. Effect of irrigation solutions for arthroscopic surgery on intra articular tissue: comparison in human meniscus-derived primary cell culture between lactate Ringer's solution and saline solution. J Orthop Res; 20:1305-10, 2002.

17- Zardeneta G, Milam SB, Schmitz JP. Elution of proteins by continuous temporomandibular joint arthrocentesis. J Oral Maxillofac Surg ; 55:709-17, 1997.
18- Kaneyama K, Segami N, Nishimura M, Sato J, Fujimura $\mathrm{K}$, Yoshimura $\mathrm{H}$. The ideal lavage volume for removing bradykinin, interleukin-6, and protein from the temporomandibular joint by arthrocentesis. J Oral Maxillofac Surg ; 62:657-61, 2004.

19- Ashraf Ghanem and Diaa Moustafa. Comparative study of single needle versus double needles arthrocentesis using Research Diagnostic Criteria for Temporomandibular Joint Disorders (rdC/tmd);Egypt Dent J. Vol. 61, No. 2, 2015.

20- Guarda-Nardini L et al. Two-needle vs. single-needle technique for TMJ arthrocentesis plus hyaluronic acid injections: a comparative trial over a six-month follow up. Int J Oral Maxillofac Surg; 41(4):506-13, 2012.

21- Sindel et al: Comparison of the efficiency of irrigation of single and double-needle techniques of temporomandibular joint arthrocentesis: A cadaver study. Cranio; 35(6):405-409, 2017.

22- Gouda AM, Elrahman HA, Askar NA. Single needle versus double needle arthrocentesis for management of patients with closed lock of temporomandibular joint. Egypt Dent J; 56:1797-1804, 2010. 